\title{
O TRABALHO NÃO AGRÍCOLA COMO ESTRATÉGIA DAS FAMÍLIAS CAMPONESAS DO AGRESTE DE PERNAMBUCO
}

\author{
NON-AGRICULTURAL LABOR AS A STRATEGY OF THE PEASANT FAMILIES IN PER- \\ NAMBUCO, BRAZIL
}

\begin{abstract}
Resumo
O presente artigo oferece uma discussão sobre a pluriatividade e o trabalho não agrícola como estratégias de reprodução camponesas. Pretende-se, com isso, compreender a multiplicidade das formas de vida e as estratégias econômicas sob as quais estão organizadas as populações rurais, em regiões nas quais existe um movimento pendular - para mais ou para menos - de combinação de atividades. Corroborando com essa discussão, trago como exemplo o Polo de Confecções do Agreste de Pernambuco, onde o trabalho não agrícola da costura vem, desde os anos 1950, sendo utilizado como uma das principais fontes de renda de algumas famílias rurais locais. A pesquisa empírica, que embasa as discussões presentes neste texto, foi realizada em três comunidades rurais da região e tem como base metodológica a observação participante, a história oral e 30 entrevistas semiestruturadas que foram realizadas com agricultores(as) e/ ou costureiros(as). Este artigo procura oferecer uma análise sob o ponto de vista antropológico, valorizando as experiências, narrativas, trajetórias e categorias de pensamento dos indivíduos que compõem o cenário da pesquisa. O estudo considera que existe um equívoco em conceber o campesinato e o trabalho não agrícola como noções excludentes. A partir desta pesquisa, pode-se perceber que o rural não se resume apenas ao agrícola e que a inserção de camponeses em processos de trabalho não agrícolas não é suficiente para indicar uma ruptura com um modo de vida.
\end{abstract}

Palavras-chave: Trabalho não agrícola. Pluriatividade. Costura.

1 Doutora e Mestra em Ciências Sociais em Desenvolvimento, Agricultura e Sociedade pela Universidade Federal Rural do Rio de Janeiro. E-mail: renatamilanes@hotmail.com 


\begin{abstract}
This paper discusses pluriactivity and non-agricultural labor as peasant reproduction strategies in order to understand the multiplicity of life forms and the economic strategies under which rural populations are organized in regions where there is a pendulum movement - for more or less - of combination of activities. Corroborating this discussion, I take as an example the Polo de Confecçôes do Agreste de Pernambuco, where the non-agricultural work of sewing since the 1950 s is used as one of the main sources of income for some local rural families. The empirical research which supports the discussions in this text was carried out in three rural communities in the region and is based on participant observation, oral history and thirty semi-structured interviews that were carried out with farmers and/or seamstresses. An anthropological point of view was adopted, valuing the experiences, narratives, trajectories and categories of thought of the individuals who constitute the research scenario. The study considers that there is a mistake in conceiving peasantry and non-agricultural work as excluding notions. From this research, it can be seen that rural labor is not limited to agriculture and that the insertion of the peasant in non-agricultural work processes is not sufficient to indicate a break with a way of life.
\end{abstract}

Keywords: Non-agricultural work. Pluriactivity. Sewing.

\title{
A PLURIATIVIDADE E O USO DO TRABALHO NÃO AGRÍCOLA COMO ESTRATÉGIAS DAS FAMÍLIAS CAMPONESAS
}

As mudanças desencadeadas pelo avanço do capitalismo, sobretudo nos séculos XIX e XX, têm demostrado uma grande habilidade das comunidades rurais de se reajustarem diante das novas condições que lhes são impostas. Face à grande multiplicidade de fenômenos aos quais os camponeses podem estar envolvidos, eles trazem consigo uma grande flexibilidade, no sentido de encontrarem "novas formas de se adaptar e ganhar a vida", como bem destacou Sha$\operatorname{nin}(2008$, p. 25).

Diante do questionamento acadêmico nas últimas décadas acerca do "conceito romântico" definidor do "camponês tradicional" e também diante de um processo de "diferenciação" do campesinato, que tem se manifestado a partir dos movimentos sociais, gerando identidades coletivas e reivindicações de direitos, torna-se necessário observar os ambientes intrafamiliares que existem atualmente no mundo rural e analisar a existência de novas formas de produção e de trabalho. Tal exercício implica em considerar os casos em que as famílias não restringem suas ocupações e formas de obtenção de renda apenas voltando-se para atividades agropecuárias, mas também ganham a vida por meio de uma combinação do trabalho agrícola com o trabalho não agrícola.

Para Shanin (2008), a resposta do campesinato às situações de crise nas quais os camponeses estão submetidos é, sobretudo, complexa. Estes grupos 
são extremamente ativos, pragmáticos e imediatos, e não ficam esperando que alguém lhes traga a solução. Além disso, as saídas encontradas para o fato de permanecer no campo e assegurar a reprodução da família são flexíveis e inventivas, pois os "camponeses têm mostrado ser extremamente resilientes e criativos em situações de crise". (SHANIN, 2008, p. 25)

Shanin (2008) considera ainda, que a família é a unidade de análise mais eficaz para se entender o campesinato, pois este se define historicamente em torno da economia doméstica e familiar, que tem seus próprios modelos, suas próprias estruturas e um significado próprio, que não desaparece ao longo do tempo. É também através da família que se definem e se determinam as atividades ou estratégias que serão capazes de manter a reprodução do grupo doméstico, seja a curto prazo ou a longo prazo.

De maneira semelhante, Carneiro (1998) também aponta que, mesmo imersa em contradições, a unidade familiar "plástica e mutante" é que tem a capacidade de elaborar novas estratégias para se adaptar frente às diferentes condições econômicas e sociais de reprodução do grupo. Portanto, é importante que um estudo que se propõe a observar a recorrência de trabalhos não agrícolas no meio rural, tenha como base a unidade familiar camponesa e suas dinâmicas constitutivas, a partir das quais são orientadas articulações com outros setores econômicos, pois é ela que organiza a reprodução social do grupo doméstico.

Levando em conta essa questão, convém pontuar que, ao longo do tempo, vários têm sido os debates nas Ciências Sociais que discutem a importância da família como uma unidade básica que apoia a estrutura da lógica camponesa, seja economicamente (ABRAMOVAY, 1992; CHAYANOV, 1981; SHANIN, 2008), seja por fatores que vão além do econômico. (CARNEIRO, 2000; COMERFORD, 2003; GALESKI, 1972; WOORTMANN, 1990)

De acordo com Almeida (1986), em geral, os trabalhos acadêmicos que buscam entender a família através de um foco mais estritamente econômico, têm como preocupação central a ideia de um modo de produção camponês, que vê na família a sustentação deste sistema. Nesse sentido, o que se destaca é um debate sobre a lógica econômica, que toma as categorias de família, trabalho e consumo como interligadas e articuladas. Já os estudos que priorizam uma perspectiva extraeconômica tratam da unidade familiar, não apenas sob a ótica de um componente funcional para a dinâmica de acumulação capitalista, mas também levam em conta outros elementos importantes para a reprodução camponesa, tais como as relações de parentesco, a ética e a moral, as relações matrimoniais, a herança e outros aspectos culturais e sociais. 
Destarte, independente do debate gerado sobre este tema e das distintas perspectivas de análise estritamente econômicas ou extraeconômicas, talvez o mais importante seja considerar que a família e o parentesco têm um papel crucial dentro das sociedades camponesas, pois são responsáveis por articular toda uma cadeia de relações sociais que estruturam o grupo do qual os indivíduos fazem parte.

Levando em conta a coletividade e as redes de relações pessoais, não se deve entender a família camponesa como uma dimensão "isolada" (pois ela não se articula apenas no interior do setor rural), mas sim como uma unidade plurisetorial, cuja lógica de funcionamento não deve ser vista e definida apenas pela produção agrícola. (MATTEI, 2007)

Assim como afirma Mattei (2007), há que se notar também que dentro de um amplo contexto de globalização e modernização, algumas mudanças vêm ocorrendo e impactando as formas de articulação das famílias, pois:

As transformações estruturais do capitalismo agrário impactaram decisivamente sobre a forma tradicional de articulação das famílias com as unidades de produção, subordinando estas às estratégias gerais das primeiras. Com isso, a incorporação de novas atividades à paisagem rural possibilitou a redefinição das estratégias das famílias, tanto em termos das ocupações como em termos das estratégias de reprodução social. (MATTEI, 2007, p. 1069)

Dentro desse contexto, o que se tem percebido é que as transformações socioeconômicas globais acabam atingindo o âmago da estrutura camponesa e modificando tanto a unidade familiar, que tende a se estreitar, passando muitas vezes de família extensa à moderna nuclear (seja por condições modernas demográficas, seja pelos próprios meios insuficientes de reprodução); como também o modelo produtivo de subsistência, pois o rural passa a assumir novas atividades que não podem mais ser resumidas à produção agrícola ou pecuária. Por essa razão, tal como também observa Carneiro (2000, p. 131):

Eleger a unidade familiar ou o grupo doméstico como unidade de observação, revela-se um procedimento fundamental para a compreensão das transformações recentes no campo brasileiro, onde o aumento das atividades não agrícolas, articuladas ou não à agricultura, exige um maior grau de complexidade analítica. 
Destarte, os camponeses na atualidade se veem obrigados a realizarem modificações importantes no que diz respeito a sua vida social e a sua forma de produção. Muitas vezes, ao dispor de poucos recursos e de restrições para potencializar a força produtiva da sua unidade doméstica, o trabalho não agrícola se torna então para o camponês uma "necessidade estrutural". (WANDERLEY, 1998) Além disso, em meio a um cenário no qual a atividade agrícola não tem a capacidade de suprir a existência no meio rural, o esforço da família camponesa se apresenta no sentido de buscar outras formas de renda, se submetendo e se adaptando a uma economia que muitas vezes "se aproveita de sua fraca mobilidade profissional". (TEPICHT, 1973, p. 26)

Vale frisar que a combinação das atividades agrícolas com outras não agrícolas para a manutenção da subsistência familiar das populações do campo, não é um fenômeno novo na história da agricultura. Kautsky e Chayanov se destacam como os primeiros autores que fizeram referência acerca de "trabalhos acessórios" e "outras atividades não agrícolas" no meio rural. (SCHNEIDER, 2003)

Kautsky, por exemplo, acreditava que a agricultura iria pouco a pouco ser sucumbida pelos ditames industriais, ou, dito de outra maneira: "o desenvolvimento do capitalismo na agricultura tende a seguir uma trajetória em que se dá sua lenta e gradual subordinação à indústria". (KAUTSKY apud SCHNEIDER, 2003, p. 80) Kautsky também já atentava para a crescente ocupação dos camponeses em indústrias a domicílio, como uma forma de "trabalho acessório", pertinente aos pequenos produtores rurais. Segundo ele, este fenômeno poderia ocorrer em regiões que possuíam pouca aptidão agrícola para firmar uma agricultura competitiva e em locais onde a indústria em domicílio detinha a vantagem de se apoiar na agricultura.

Já para Chayanov, a busca de atividades complementares no meio rural se constituía como uma estratégia de alocação da força de trabalho familiar, frente aos condicionantes da unidade produtiva agrícola. Para este autor, ao ser adotada, essa estratégia poderia expressar: "o sentido da racionalidade que a família imprime às suas atitudes para manter o balanço entre trabalho e consumo e garantir sua reprodução". (CHAYANOV apud SCHNEIDER, 2003, p. 84)

No início, dentro da literatura acadêmica, essa estratégia da combinação de atividades dos camponeses foi vista tanto como uma "fase de transição", assim como algo que poderia resultar no fim do campesinato, pois a própria noção de "dupla atividade" expressava, por vezes, um processo de diferenciação 
e de mudança que estava em curso, e que resultaria no "desaparecimento" dos pequenos agricultores que eram considerados "inviáveis" dentro do contexto da modernização rural. (CARNEIRO, 1996, p. 90)

Dentro desse contexto, visando dar conta de entender todos esses fenômenos que estavam acontecendo no mundo rural, em meados da década de 1980 a noção de "pluriatividade" entra em cena, inicialmente no debate francês e depois ganha força em outras partes do mundo, inclusive no Brasil. Segundo Schneider (2003), essa noção embora seja bastante genérica, pode ser definida resumidamente como a combinação de duas ou mais atividades realizadas pelos camponeses, sendo uma delas a agricultura. Este fenômeno tenta expressar ainda, as situações nas quais as famílias camponesas, devido à fragilidade social e econômica sob as quais estão submetidas, recorrem às atividades não agrícolas, no intuito de buscar empregos externos ao seu contexto e novas formas de assalariamento.

Para os fins deste artigo, o que evidencia a importância sumária acerca da pluriatividade é a intrínseca relação que se estabelece entre o mundo rural e a sociedade industrial, que não podem ser vistas como fenômenos antagônicos. Sendo assim, é importante assumir este tema, sob a perspectiva de mostrar que existe um equívoco, muitas vezes difundido no meio acadêmico (sobretudo em alguns debates marxistas), em conceber o campesinato e o mercado de trabalho como noções em posição mútua de exclusão em que, para que um exista, o outro teria que deixar de existir.

Um dos autores que ajuda a desconstruir o equívoco anteriormente citado é Garcia Jr. (1989), que ao tentar compreender a multiplicidade dos efeitos dos deslocamentos dos trabalhadores do Brejo e do Agreste da Paraíba, em direção ao mercado de trabalho do Sudeste, atenta para o fato de que não existe uma trajetória única no desenvolvimento capitalista, na qual a reprodução ampliada da existência de trabalho assalariado signifique a negação insofismável do campesinato. Ao contrário, o caso analisado por ele demonstra que a reprodução do campesinato é simultânea e não oposta ao crescimento do proletariado urbano e industrial. Além disso, Garcia Jr. (1989) percebeu que o trabalho no Sudeste do país era um mecanismo que assegurava a permanência das famílias agrícolas dos migrantes nas suas propriedades.

Se aproximando do que propõe Garcia Jr. (1989) e em acordo com Wanderley (1998), acredita-se, portanto, que a pluriatividade não necessariamente representa a desagregação da agricultura camponesa, mas pode contribuir para a viabilização de estratégias de reprodução presentes e futuras com as quais a família pode contar. Muitas vezes, o trabalho não agrícola ou pluriativo, pode 
ser considerado como uma "resposta" ou até mesmo uma forma de resistência em meio às crises econômicas e até mesmo climáticas em que estão envolvidas as famílias rurais e das quais não podem sair, pois como afirma Carneiro (1996), os espaços abertos para a prática de atividades complementares não agrícolas são, em sua maior parte, as regiões desfavoráveis ou que se encontram incapacitadas para a intensificação da agricultura. Portanto, o que se percebe é que, longe de significar um processo linear "evolutivo", que afastaria o camponês do meio rural, a possível combinação de atividades ressalta cada vez mais a complexidade das formas e dos elementos utilizados por alguns atores para garantir a reprodução do núcleo familiar, assim como veremos a seguir, através do exemplo do Agreste pernambucano.

A pesquisa de campo que orientou as reflexões trazidas neste artigo foi fruto de uma dissertação de Mestrado, na qual foram realizadas trinta entrevistas semiestruturadas, entre 2013-2015, com agricultores(as) e/ou costureiros(as) da zona rural ${ }^{2}$ do Agreste pernambucano. Além das entrevistas, também foram utilizadas a observação participante, a história oral e a etnografia com a intenção de compreender e reelaborar os significados e as particularidades das ações dos indivíduos nas suas práticas e representações do cotidiano.

\section{O SURGIMENTO DO POLO DE CONFECÇÃO DE ROUPAS NO AGRES- TE DE PERNAMBUCO}

O Polo de Confecções do Agreste de Pernambuco consiste em um dos mais importantes aglomerados econômicos existentes na Região Nordeste, particularmente no setor de confecções (atualmente é o segundo maior polo têxtil do Brasil). O Polo produz, basicamente, roupa casual (masculina e feminina), brim (jeans, bermuda, saias, shorts e camisas), malharia (camisetas, tops, blusas, vestidos), moda infantil e lingerie. Suas atividades produtivas e comerciais se encontram instaladas principalmente nas cidades de Santa Cruz, Toritama e Caruaru, englobando também alguns povoados rurais da região.

Esse espaço se situa em uma região que, antes de se ocupar com a produção e comercialização de roupas, tinha como principal fonte de trabalho e renda, a agricultura. $O$ período que marca o início de uma dinâmica socioeconômica de tipo mais industrial e comercial, tem a ver com o quadro de di-

2 O campo empírico da pesquisa faz parte da zona rural do município de Taquaritinga do Norte, Pernambuco. As comunidades pesquisadas foram: Vila do Algodão, Assentamento Nova Esperança, Sítio Situação do Algodão e pequenas propriedades no entorno dessa região. 
ficuldades historicamente dadas no Nordeste enfrentadas pela população, no que diz respeito à escassez dos meios de sustento. Situação essa, que sempre se agravava em períodos de seca e que sofreu, nos anos 1950, um revés ainda mais contundente com a crise do algodão. Com a crise da cotonicultura, provocada pelas condições climáticas e pela praga do bicudo, os moradores locais passaram a viver dentro de um contexto de recursos limitados para a produção no meio rural, que ameaçava a reprodução social de suas famílias. Tal contexto fez com que se tornasse necessária a busca de novas estratégias geradoras de renda, dentre as quais as pessoas encontravam nas atividades não agrícolas, o sustento econômico e social do grupo doméstico.

Neste período de crise, uma das "saídas" encontradas por esses pernambucanos foi, correntemente, a migração dos moradores da região para o Sul/ Sudeste do país, fator este influenciado pelo período de grande industrialização que o Brasil vivia na época. Outras estratégias também foram perseguidas e uma delas se traduziu na produção e comercialização de roupas em feiras locais, denominadas de "Feiras da Sulanca".

A "Feira da Sulanca" surge em meados de 1950 com a iniciativa de alguns comerciantes de Santa Cruz do Capibaribe, que se deslocavam para Recife levando galinhas, carvão, queijo, entre outros produtos locais para vender, e retornavam com retalhos de tecidos para suas casas. Estes passaram a ser convertidos, pelas mulheres da zona rural da região, em colchas, assim como em peças de vestuário para uso familiar. Depois essas peças passaram a ser costuradas para a venda em feiras do sul do Estado e nas cidades de Estados vizinhos. Todas as mercadorias tinham como principal atrativo o preço baixo, as peças eram simples, sem muita diversificação e se destinavam geralmente às populações de baixa renda. (LIRA, 2006)

Mesmo sem amparo estatal, o sucesso das vendas fez com que a oferta se expandisse, principalmente nos anos 1960 e 1970, pressionando assim a busca por uma maior quantidade de tecidos para abastecer a produção. Estes começaram a ser trazidos do Rio de Janeiro e de São Paulo pelos caminhoneiros da época, e consistiam em retalhos e resíduos que "sobravam" das confecções das grandes cidades do Sudeste. Alguns motoristas também adquiriam as peças e comercializavam em outras partes do país. Esse processo foi dando certo e a "Feira da Sulanca" passou a ganhar uma repercussão para além dos limites locais.

Com o aumento da demanda de mercado, algumas pessoas passaram a investir em máquinas industriais de baixa rotação, porque as máquinas manuais e domésticas já não davam mais conta do processo produtivo. Isso fez com 
que a qualidade dos produtos melhorasse e as vendas se ampliassem para pessoas de diferentes classes sociais.

As décadas de 1980 e 1990 constituíram o auge do desenvolvimento produtivo e comercial da região. Nessa época ocorreu o retorno de várias pessoas que antes haviam migrado para o Sul/Sudeste do país, com o intuito de voltar para investirem no ramo de confecções. Aliado a esse movimento, surgiu também um fluxo de migração rural dos sítios do Agreste de Pernambuco, e até mesmo de Estados vizinhos, para o Polo, todos em busca de emprego, o que acarretou um demasiado aumento populacional nas três cidades principais: Caruaru, Toritama e Santa Cruz. Além do aumento populacional, o crescimento econômico da região ganhou destaque e foi cada vez mais impulsionado pela fabricação de roupas, ao passo que se tornou necessário aumentar e ampliar demasiadamente a produção, pois semanalmente a região passou a receber muitos compradores de todos os lugares do país.

A "Feira da Sulanca" passa a se chamar "Polo de Confecções do Agreste de Pernambuco", ${ }^{3}$ a partir de 2000 . Isso decorre do empenho por parte de alguns empresários e comerciantes em desconstruir a imagem da Sulanca, que na atualidade é relacionada a produtos de pouca qualidade, e seu uso pode ser pejorativo. Dessa maneira, como Véras de Oliveira (2011, p. 23) observa: “Operou-se uma reelaboração discursiva visando pôr no lugar da 'Feira da Sulanca' o 'Polo de Confecções'; no lugar de 'sulanqueiro', a denominação 'empresário' ou 'empreendedor".

Além dos espaços de comercialização no Polo, é comum encontrarmos microunidades de produção familiares por toda parte, normalmente instaladas nas próprias residências dos trabalhadores (misturando-se utensílios domésticos, equipamentos industriais e matérias primas), nas formas de "fabricos" e "facções". Estes empreendimentos são os principais responsáveis por sustentar e garantir a confecção das mercadorias que posteriormente serão vendidas nas feiras ou nos shoppings populares. A separação do processo de trabalho que ocorre no caso do Polo, terceiriza e divide a confecção das peças para ser feita em vários locais diferentes. Antes do surgimento da Sulanca, ${ }^{4}$ a produção da peça inteira era feita apenas por uma pessoa, agora, devido à produção em larga escala, os trabalhadores são contratados por empresas maiores para desenvol-

3 Vale ressaltar que embora os centros principais do Polo sejam Santa Cruz, Toritama e Caruaru, esse espaço se abrange a outros municípios tais como Taquaritinga do Norte, Brejo da Madre de Deus, Jataúba, Vertentes, Riacho das Almas, São Caetano, Surubim etc.

4 A definição do termo "sulanca" será explicitada mais adiante. 
ver apenas algumas tarefas específicas, não tendo no final uma visão da peça totalmente finalizada.

Dentre as inúmeras configurações possíveis, o Polo tem sido caracterizado por alguns autores como um espaço que conta com a forte presença da produção domiciliar de caráter informal (tanto na zona urbana, como na rural) e suas unidades de produção se destacam tanto por se apoiarem nas relações de trabalho familiares, como também por evidenciarem a predominância do trabalho feminino e infantil na região. (VÉRAS DE OLIVEIRA, 2011; BEZERRA, 2011, SILVA, 2009)

\section{A COMBINAÇÃO DE ATIVIDADES AGRÍCOLAS COM A COSTURA}

De acordo com Véras de Oliveira (2011), as relações de trabalho no Polo do Agreste pernambucano reconfiguraram a dinâmica urbano-rural da região. Quanto a isso, pode-se destacar o fato de que muitos moradores do campo migraram para as cidades em busca de novas chances de trabalho, outros passaram a trabalhar com a costura na zona rural, e existem ainda os casos das pessoas que, embora morando atualmente nas cidades, continuam mantendo uma casa nos seus sítios apenas para fins de lazer. Nesse sentido, o meio rural na região apresenta características semelhantes ao meio urbano no que diz respeito às atividades produtivas de confecções, pois desde esse período até os dias atuais, em alguns sítios da região é comum andarmos pela zona rural de Santa Cruz do Capibaribe, Toritama e Caruaru e nos depararmos com o barulho das máquinas de costura, em quase todas as casas, onde por trás das mesmas estão inúmeras mulheres e alguns homens trabalhando para o sustento familiar. Dessa manei$\mathrm{ra}$, atualmente o espaço rural dessa região não se destina exclusivamente para atividades agropecuárias, pois ele passa a ser reintegrado também à dinâmica produtiva de roupas e como um local de "distração" e "fuga" das atividades industriais e comerciais do Polo.

O Agreste de Pernambuco faz parte de uma região denominada "polígono das secas", 5 que corresponde à área mais seca do país, onde as chuvas são irregulares e escassas. Levando em conta a estrutura produtiva e as condições climáticas locais, as estiagens ou a "falta de inverno" são temas que estão sempre presentes nas falas dos moradores locais, pois a ausência de chuvas nunca permitiu aos pequenos produtores uma forma que lhes garantisse viver e se de-

5 A região denominada de "polígono das secas" possui um índice pluviométrico anual de aproximadamente $500 \mathrm{~mm}$. 
dicar apenas à plantação agrícola. Aliado a isso, o descaso político, assim como a ineficiência e a falta de planejamento também demonstram que o Agreste pernambucano não tem encontrado historicamente um forte apoio público no sentindo de minimizar os velhos e conhecidos danos que decorrem das estiagens e que vem se repetindo por décadas. Uma das agricultoras entrevistadas, por exemplo, me informou com total convicção que: "ninguém vive mais só de agricultura por aqui. Aqui mesmo é um sítio, mas não chove, aí você vai viver de quê? Vai morrer de fome se não arrumar outra coisa!". Para ela: "Se você é do sítio, hoje em dia tem que saber costurar, porque se for esperar pela agricultura não tem como sobreviver. Esse ano mesmo, ninguém lucrou nada".

Muito semelhante ao caso dos cortadores de cana do Sertão paraibano analisado por Cover e Menezes (2020), a região na qual essas pessoas moram tem um baixo índice de oferta de empregos e, por essa razão, a busca de atividades econômicas diversas é indispensável para a manutenção da unidade doméstica das famílias locais. Além do mais, o contexto dos sertanejos paraibanos se aproxima muito aos camponeses do Agreste pernambucano, pois como demonstram os autores, diante da escassez de terras, da falta de água, da ausência de crédito e assistência técnica, os pequenos proprietários rurais estudados por eles "não tinham capital para se tornarem criadores de gado e dependiam da comercialização do algodão para garantir a parte monetária de sua subsistência. São frágeis às crises de produção na região, em geral, causadas pelas secas". (COVER E MENEZES, 2020, p. 460)

No caso do Agreste pernambucano, as dificuldades crescentes que sempre afetaram a agricultura se impõem como um obstáculo para a manutenção das famílias. Nesse sentido, o crescimento do setor de confecções de roupas acabou estimulando outros arranjos na lógica de reprodução social. O que vem acontecendo na região é um processo de revitalização das formas de produção e de reprodução da força de trabalho, que combinam a atividade da costura com a atividade agrícola e configura o que se tem designado como fenômeno da pluriatividade, tal como sugere Mattei (2007).

$O$ fato do dinheiro da sulanca ter se tornado a principal fonte de renda na região e ter melhorado as condições de sobrevivência das pessoas da zona rural, também foi apontado por um dos agricultores locais ao afirmar que: "a sulanca aqui foi a salvação da gente! A gente vive mais no campo e na sulanca para ir arrumando o pão mais fácil. Eu acho que $90 \%$ da nossa região aqui sobrevive por causa da sulanca", pois como ele complementa a seguir: "mesmo que a gente trabalhe de pedreiro e de outras coisas, mas se a sulanca afracar lá, nós ficamos aqui sem serviço". Dessa maneira, o passado de "não ter nada", de 
pobreza e miséria, começa a ser transformado e relatado através da atividade costura, que é vivida como algo que melhorou a vida da população local, porque emprega muitas pessoas na atualidade.

$\hat{E}$ nesse sentido que $o$ assalariamento surge para alguns(as) agricultores(as) como uma alternativa ou estratégia que visa responder às dificuldades enfrentadas pelo seu grupo doméstico. Percebe-se ainda, que a dimensão agrícola também é determinante no que diz respeito a esse fenômeno, pois as regiões onde a agricultura não produz o suficiente para manter a reprodução familiar se tornam mais propícias a esse tipo de combinações de atividade, ou mesmo a preferência por executar atividades não agrícolas.

Outro fator muito interessante revelado pela pesquisa é que as comunidades rurais mais próximas dos centros urbanos de Santa Cruz, Toritama e Caruaru foram incorporadas mais intensamente no que diz respeito às atividades de confecções do que os sítios que ficam mais distantes geograficamente destes municípios.

Destarte, a extensão das propriedades, a distância entre as comunidades rurais e o meio urbano, o acesso à terra e aos meios de produção, a demarcação de gênero, o apego, afeto ou "amor" pela tradição agrícola, os percalços climáticos e a possibilidade de novas fontes de renda, podem ser fatores determinantes para que se possa entender a multiplicidade e as diferentes maneiras de inserção nas atividades do Polo e a sua possível relação (ou não) com as atividades agrícolas, que por sua vez podem permanecer ou diminuir diante da inserção das famílias rurais no mercado de trabalho de roupas.

Porém, mesmo enredados em um contexto de escassez de chuvas e recursos hídricos, cabe salientar que a falta de água não é sinônimo da ausência de agricultura na região, pois mesmo com as recorrentes estiagens, nos sítios e assentamentos, "todo mundo sempre bota um roçadinho". A pesquisa de campo revelou que alguns agricultores, sobretudo os homens mais velhos, se mantêm resilientes e continuam plantando seus roçados e resistindo frente às crises climáticas e aos riscos do fracasso na colheita. Para entender essa questão, convém pontuar o que sinaliza Wanderley (2000) ao afirmar que, mesmo quando os agricultores são economicamente fragilizados e socialmente minoritários, a atividade agrícola permanece "real e simbolicamente" como um dos eixos definidores das suas identidades.

No caso do Agreste de Pernambuco, o que se percebe é que a motivação destes agricultores e costureiros para manter a atividade agrícola é muito mais social e cultural do que meramente econômica, pois essa atividade está inserida em um modo de vida. Dessa forma, "continuar plantando um roçadinho" se 
revela importante para a manutenção de vários elementos, tais como da identidade social, do patrimônio familiar, assim como das redes de solidariedade e de sociabilidade. Do outro lado, o trabalho com a costura também pode ser como uma maneira que essas famílias encontraram para permanecerem no campo, pois a possibilidade de trabalhar em casa com as confecções evita que essas pessoas migrem para a cidade em busca de emprego.

No que diz respeito às combinações de atividades agrícolas com outras formas de renda responsáveis pela manutenção e reprodução das famílias camponesas pesquisadas, consegui identificar três principais possibilidades existentes na região, seriam elas: 1) a produção agrícola existe, mas não consegue se destacar mais do que a produção de roupas no que diz respeito ao subsídio do sustento familiar, por isso ela é combinada com a costura (esse exemplo corresponde aos casos das famílias que vivem nos sítios e assentamentos); 2) existe um abandono agrícola e o que se mantém nas residências é apenas a confecção de roupas, que acaba sendo a responsável pela maior parte da renda familiar (esse caso corresponde à uma vila rural localizada mais próxima da cidade); e 3) existe ainda a possibilidade onde a renda da família provém tanto das confecções têxteis e da agricultura, como também de outras atividades não agrícolas, como por exemplo, a comercialização de produtos têxteis, a prestação de serviços, a inserção das mulheres em serviços domésticos e dos homens no trabalho na construção civil, a comercialização de produtos têxteis, dentre outras possibilidades. Cabe lembrar, todavia, que essas formas de combinações não são as únicas possíveis e elas também podem variar e ocorrer de maneira distinta, a depender do contexto particular em que cada grupo familiar está inserido.

Detalhando melhor essas variações encontradas, percebe-se ainda que, nos sítios e assentamentos nos quais os terrenos são maiores e propícios para pequenas plantações ou pecuária, não houve um abandono agrícola por completo, pois as famílias continuam mantendo algum roçado e a criação de galinhas, bodes, vacas e porcos. Além disso, por mais que o trabalho com a costura assuma o papel de principal responsável pela maior fonte de renda no domicílio, a atividade da costura é vista como uma "complementação" ou "combinação" nos rendimentos da família, de forma que o dinheiro adquirido com a confecção pode ser investido na agricultura e vice-versa. Todavia, deve ser acentuado que o peso das rendas não agrícolas, como também da agricultura, não segue um padrão, pois os limites de uma ou outra atividade, o fato de manter as duas ou de optar apenas por uma e abandonar a outra, podem variar de acordo com cada família. 
A agricultura, por sua vez, embora mantida como uma atividade parcial, também é conciliada com a produção de roupas e permite aumentar a renda do lar, pois quando é preciso, outras estratégias também são acionadas, como, por exemplo, a venda de animais ou dos seus derivados para comprar uma máquina de costura ou outro bem que a família esteja necessitando. Especificamente em casos desse tipo, a agricultura é referenciada pelos entrevistados como algo que faz parte do modo de vida e as falas sempre exaltam o "amor pela terra", a "vocação pela profissão" e as "raízes agrícolas". Isso significa dizer que, mesmo existindo como uma atividade marginal, há uma valoração de cunho emocional colocada tanto na agricultura como na terra, que manifesta uma forte simbologia afetiva.

Diferente dos sítios e assentamentos, na vila rural, justamente por ser mais próxima da cidade de Santa Cruz do Capibaribe, a situação se configura de maneira diferente, pois as pessoas que moram neste local não desenvolvem mais nenhum tipo de atividade relacionada à agricultura ou pecuária, elas se mantêm apenas costurando. Fato este que reafirma a hipótese de que quanto mais perto a comunidade rural estiver das cidades sedes do Polo, maior será o abandono agrícola, pois a região e os moradores estarão mais fortemente vinculados à atividade de produção de roupas. A exemplo disso, convém destacar o depoimento de um dos agricultores entrevistados, que ao ser questionado se o pessoal da sua comunidade vive mais através da renda da costura ou da agricultura, assim me respondeu: "são os dois aqui na região da gente, pra cá pro sítio ainda tem agricultura e sulanca, mas já pegando ali na Vila do Algodão, o povo ali só costura mesmo". Ele ainda conclui dizendo que: "vamos dizer que nós aqui somos meio a meio, entendeu? Os mais velhos na agricultura e os mais novos tão tudo na sulanca".

A articulação dessas duas esferas volta a ser descrita por outro agricultor chamado João, que ao explicitar sua rotina diária e como ocorre na prática a "mistura" da sulanca com o trabalho na roça, me fala: "eu acordo cedinho, ajeito a ração dos animais e quando é no tempo de inverno mesmo, o cabra tira dois, três dias na semana só para trabalhar na roça. $\mathrm{E}$ as vezes a gente ganhando na sulanca a gente se vira, paga um ou outro para ajudar aqui". Ele conclui sua fala dizendo ainda que: "hoje em dia a renda daqui da agricultura é pouco, mas eu crio umas cabras, aí mato um bode e vendo a carne, vendo um porco, vendo o ovo da galinha, aí mistura com o ganho da sulanca".

João confirma ainda que as pessoas que são ligadas às confecções de roupa reinvestem nos sítios, a renda obtida com o trabalho não agrícola da costura, pois como afirma: "o cabra aqui tira da sulanca e emprega na agricultura, pra 
comprar um bode, um garrote, um porco". Complementando sua fala, é interessante perceber ainda, que esse processo de complementação de rendimentos tem uma via dupla, pois os ganhos obtidos com a agricultura também podem ser reinvestidos na sua confecção de roupas doméstica, tal como aponta João: "aí as vezes, quando o cabra já tem quatro ou cinco bichos, aí ele pensa assim:vou vender esses bichos e investir na sulanca, comprar mais máquina, montar uma facção e assim vai. Uma coisa vai ajudando a outra, né?".

A experiência trazida por João demonstra que o próprio dinheiro obtido com a costura não só é reinvestido na agricultura e na criação dos animais, mas até permite que ele também possa contratar mais alguém para auxiliá-lo na lavoura. Além disso, embora a agricultura assuma um peso menor na renda final dos domicílios rurais, isso não impede que os ganhos obtidos com as atividades agropecuárias também possam ser direcionados para as confecções de roupas.

Os exemplos do Polo se assemelham bastante ao contexto do sertão da Paraíba estudado por Cover e Menezes (2020), no qual os autores observaram que a migração sazonal das pessoas dessa região para o corte de cana no $\mathrm{Su}$ deste acabou possibilitando a vários trabalhadores da zona rural a compra de lotes de terra para que eles se estabelecessem como pequenos proprietários rurais. Segundo Cover e Menezes (2020, p. 469), durante a pesquisa de campo na Paraíba, eles ouviram muito a explicação dos entrevistados de que: "através do corte de cana, a vida das famílias tinha melhorado, e que muitos passaram a ter terra, casa e moto por causa do dinheiro proveniente do assalariamento nas usinas canavieiras". Os autores perceberam que os recursos obtidos com o assalariamento no corte de cana assumiam uma importância muito significativa na renda das famílias sertanejas, não só no que diz respeito ao sustento de itens básicos, como alimentação e moradia, mas também pelo fato de possibilitar investimentos de outra natureza, como, por exemplo, a compra de motos, carros e a compra ou reforma de casas e terrenos.

Entretanto, embora os benefícios econômicos dessas estratégias sejam muito relevantes para as famílias rurais, convém destacar que no Agreste pernambucano, o processo de incorporação desses agricultores no mercado de trabalho também tem seus custos. Com relação a isso, convém pontuar que o crescente interesse da contratação dos camponeses pelos empresários locais, se justifica pelo preço mais baixo da mão de obra rural em comparação aos trabalhadores da cidade, para desenvolverem a mesma atividade. Some-se isso ao fato de que a lógica inerente do setor têxtil sempre foi influenciada pelo aumento da produção e pela redução dos custos. Nesse sentido, a subcontratação se revitaliza atualmente através de uma dinâmica que mantém relações 
contínuas entre o formal e o informal, deslocando os processos produtivos para setores rurais ou peri-urbanos.

É, portanto, dentro deste cenário que emergem também novas relações de trabalho atrativas para a mão de obra disponível e ociosa do campo, permitindo cada vez mais que os limites industriais saiam do urbano e adentrem o rural. Schneider (1994, p. 16) descreve processos desse tipo da seguinte maneira: "as indústrias, visando ampliar a acumulação de capital, descentralizam suas unidades de produção para o meio rural e repassam a terceiros e subcontratados a execução de determinadas fases do processo industrial".

Carneiro (2006, p. 102) aponta que a relação entre o setor agrícola e o setor industrial sempre foi um componente importante, tanto da lógica do processo de capitalização das empresas, bem como do processo de reprodução social das famílias agrícolas. De acordo com a autora: "as formas transitórias assumidas pela indústria de confecção na sua origem - a manufatura, 0 artesanato em domicílio - persistiram, transformando-se em características estruturais do processo de produção e coexistindo com a produção fabril propriamente dita".

O que se percebe através do caso do Polo é que há um claro interesse logístico dos empresários locais em descentralizar a produção para áreas periféricas, onde os custos pesam menos no orçamento total. Nesse sentido, atualmente existe uma procura muito grande por locais com pouca infraestrutura, baixa fiscalização e mão de obra barata e abundante. Todos esses elementos passam a ser encontrados no campo, sobretudo nos espaços em que a agricultura vem perdendo a importância como meio de vida e de trabalho. $O$ trabalho com a costura, por sua vez, acaba entrando em cena e assumindo um peso cada vez maior na renda dessas famílias.

Muito semelhante ao caso do Brejo paraibano, analisado por Garcia Jr. (1989), a prática da combinação das atividades agrícolas com não agrícolas no Agreste pernambucano, não corresponde a um fenômeno particular, que é estranho a lógica de reprodução social camponesa local, mas ao contrário, foi e é, desde sempre, um dos múltiplos mecanismos que vêm sendo acionados para complementar a renda das famílias camponesas do interior do Nordeste. Dessa maneira, o possível recurso às múltiplas e diversificadas atividades não estaria "rompendo com um padrão de reprodução social, mas ao contrário, seria a expressão de uma maneira de exercer a condição de agricultor", conforme bem aponta Carneiro (2006, p. 175).

Para além do que já foi discutido, é importante atentar para o fato de que, no Agreste pernambucano, a inserção dos camponeses em atividades não 
agrícolas se deu num nicho precário de mercado, no qual a força de trabalho dessas pessoas foi incorporada pelos empreendimentos do Polo sob um preço muito inferior ao dos trabalhadores urbanos. Dessa forma, embora as atividades de confecção de roupas possam ser consideradas como fontes de renda para muitas famílias rurais da região, acredita-se que essa dinâmica de mercado tem também seu preço. Pois, do outro lado estão os empregadores, que imersos em um ambiente muito competitivo, buscam flexibilidade, redução de custos e transferência de riscos e tudo isso passa a ser feito às custas do não cumprimento de encargos trabalhistas e da informalização do emprego, que tem como uma das principais consequências "a precariedade dos empregos e das condições de trabalho a que são submetidos os trabalhadores". (SCHNEIDER, 1994, p. 159)

A redução de custos dos contratantes é garantida também pelo regime de ganho por produção, dessa maneira o trabalho flexível se torna usual e se expressa nos subcontratos de fabricos e na terceirização de serviços (feita por empresas maiores) que recorre às facções, tendo como consequência a precarização nas condições de trabalho. Ao dividir a produção em microunidades, as empresas diminuem o custo das mercadorias e acabam se "livrando" de muitos direitos sociais que deveriam ser garantidos por lei, caso os contratos fossem formalizados. Sendo assim, a informalidade combinada à intensificação do trabalho (com a produção em série em grandes quantidades) e ao trabalho domiciliar, garante o baixo custo das mercadorias do Polo e também exige dos(as) costureiros(as) um maior dispêndio de horas trabalhadas para que se possa receber uma maior remuneração.

\section{CONSIDERAÇÕES FINAIS}

Os camponeses têm demonstrado ao longo do tempo uma grande flexibilidade e multiplicidade de respostas em face dos desafios e das crises econômicas que eles enfrentam, acionando muitas vezes recursos ou trabalhos que se distanciam de uma realidade agrícola, para com isso sustentar a reprodução da sua família. Em alguns casos, o fato das populações rurais exercerem atividades não agrícolas (sobretudo em meio a um contexto de estagnação), não deve ser visto apenas como um processo de "proletarização" do camponês ou uma "descampesinação" do mesmo, mas ao contrário, tais atividades podem ser requisitos fundamentais até mesmo para a permanência da unidade familiar no campo, pois muitas vezes, a remuneração que advém de outras esferas re- 
presenta para alguns grupos a única (ou a maior) forma de ingresso de renda nos domicílios.

Semelhante ao caso do Brejo paraibano analisado por Garcia Jr. (1989), no Agreste pernambucano a prática da combinação das atividades agrícolas com não agrícolas não corresponde a um fenômeno particular, que é estranho à lógica de reprodução social camponesa local, mas ao contrário, foi e é, desde sempre, um dos múltiplos mecanismos que são acionados para complementar a renda das famílias camponesas conforme as necessidades dos grupos domésticos.

Tal como foi demonstrado através da pesquisa de campo, o aumento das atividades não agrícolas não resulta necessariamente no abandono completo ou permanente do espaço rural ou das atividades agrícolas, pois existe uma complementação de renda mediante aos distintos trabalhos realizados. Dessa forma, as diferentes rearticulações entre as esferas e o possível recurso às múltiplas e diversificadas atividades não estaria nesse contexto, "rompendo com um padrão de reprodução social, mas ao contrário, seria a expressão de uma maneira de exercer a condição de agricultor", conforme aponta Carneiro (2006, p. 175), ou seja, seria uma forma desse campesinato se reconfigurar diante dos desafios cotidianos.

Destarte, fugindo de um debate que constrói tipologias ou classificações, devemos estar atentos para que a noção de pluriatividade não seja vista com ingenuidade nem categorizada de maneira positiva ou negativa, mas sim como algo que designa um processo social e, como o próprio nome diz, "plural", e isso significa reconhecer processos incorporadores de atividades não agrícolas como constitutivos da própria dinâmica social da agricultura familiar, como afirma Carneiro. (1999, p. 326)

Partindo para uma análise mais ampla, o crescimento das atividades não agrícolas não só no Agreste pernambucano, mas também em outras regiões do país, vêm se constituindo como um elemento muito importante na atual fase de desenvolvimento da economia rural, pois têm criado novas oportunidades de trabalho para as famílias, viabilizando práticas e estratégias dentro e fora dos estabelecimentos e também têm se apresentado como alternativa de renda complementar aos ganhos obtidos com as atividades agrícolas. Diante desse fenômeno, o que evidencia a grande relevância acerca do trabalho não agrícola (da costura) na região pesquisada é a intrínseca relação que o rural (outrora marcado mais fortemente pela produção agrícola) e o industrial (frequentemente associado com o "urbano") não podem ser vistos como antagônicos. 
A partir deste caso empírico em específico, pode-se constatar, por exemplo, que o rural não se resume apenas ao agrícola e que a inserção de agricultores em processos de trabalho não agrícolas, não são suficientes para indicar uma ruptura com um modo de vida. Além do mais, o aumento das atividades não agrícolas no meio rural não deve ser entendido e interpretado de maneira precoce como uma perda de importância das atividades agrícolas por completo. Nesse sentido, através do caso do Polo, é importante perceber que longe de significar uma fase de transição e um processo linear que afastaria o agricultor do meio rural ou algo que poderia resultar no fim do campesinato, a possível combinação de atividades, ou a recorrência ao trabalho não agrícola da costura ressalta cada vez mais a complexidade das formas e dos elementos utilizados por alguns atores para garantir a permanência da unidade familiar no meio rural. Além disso, essa combinação de atividades pode ser entendida tanto como uma forma de aumentar o rendimento familiar ou individual, como também pode ser uma oportunidade de inserção econômica e social das mulheres em uma profissão remunerada.

Sendo assim, é importante, que as atividades "industriais" exercidas pelas populações do campo devam ser entendidas, também, como estratégias familiares dos grupos, nas quais se exploram novas possibilidades de inserção da mão de obra, pois em contextos de limitações da produção agrícola, a agricultura não tem mais capacidade de absorver o trabalho do núcleo da família disponível, então, esse papel fica destinado aos setores urbanos ou industriais, que se apresentam na maioria das vezes como as únicas formas de complemento ou de ingresso da renda para a reprodução econômica dos mesmos. Nesse sentido, o meio rural entra em cena como o sustentáculo desse sistema e passa a ser utilizado como resultado da convergência de duas estratégias: "de um lado, encontra-se o capital buscando introduzir novas formas de expropriação da mais-valia ${ }^{6}$ e da ampliação do lucro, e do outro, a família na qual se estabelece uma divisão sexual do trabalho que visa garantir à reprodução do seu núcleo". (SCHNEIDER, 1994, p. 304)

Convém destacar que, no Agreste de Pernambuco, o trabalho domiciliar da costura vem, desde os anos 1950, incorporando inúmeras pessoas da região, o próprio caráter familiar dos empreendimentos pode aparecer no discurso de algumas pessoas como um trabalho "mais confortável", por estar sendo realizado no seu lar ("sem a presença de patrões" para lhes ditarem ordens). Essa "liberdade profissional", no entanto, traz consigo algumas consequências, como,

6 Para mais detalhes sobre a forma como Schneider utiliza o conceito de mais-valia, proveniente das obras de Karl Marx, conferir Schneider (1994). 
por exemplo: jornada de trabalho indefinida ultrapassando as horas estipuladas socialmente para a realização do trabalho profissional, a mistura dos papéis reprodutivos com os produtivos, ${ }^{7}$ o envolvimento de crianças e idosos para "ajudarem" a atender as demandas solicitadas no tempo estipulado, dentre outras.

O que se percebe no local é que o setor informal, evidenciado pela produção de confecções têxteis, apareceu como uma oportunidade de atividade rentável para inúmeras famílias camponesas que se viam impossibilitadas de manter sua reprodução social apenas com atividades agrícolas. Ademais, sob as franjas do capitalismo periférico e o espírito do capitalismo moderno, para o camponês do agreste de Pernambuco "a condição de precariedade transforma o presente em algo contra o qual não se pode lutar; ele se impõe enquanto necessidade". (SOUZA, 2012)

Dessa forma, as atividades de caráter familiar e domiciliar geralmente encontram suporte nas condições de trabalho precárias, flexíveis e subcontratadas, semelhante ao que ocorre na China e é relatado no texto de Castro (2012). Todavia, atentar para essas questões não significa desconsiderar a total relevância que a costura tem enquanto uma fonte rentável de subsistência para a população camponesa do Agreste pernambucano, que se encontrava com a reprodução ameaçada devido à insustentabilidade da produção agrícola local pois, embora seja precário, este tem sido um trabalho que lhes permite adquirir uma renda garantida, que não depende das intempéries da colheita agrícola. No entanto, o que deve ser percebido é que dentro de um processo de incorporação da mão-de-obra rural feita por um mercado informal, algumas consequências se evidenciam como alarmantes no que diz respeito às condições de trabalho.

Portanto, embora o trabalho não agrícola ou pluriativo no Polo possa ser considerado como uma oportunidade indispensável para manter a reprodução de muitas famílias camponesas, acredita-se que essa dinâmica de mercado tem também seu preço, pois se mantém em meio a um contexto no qual a intensificação do trabalho se torna uma característica comum no local e se revela através das jornadas que duram até 15 horas por dia, através da utilização do trabalho infantil, do adoecimento dos trabalhadores por conta de produtos tóxicos utilizados na tinturaria, da inalação dos pelos dos tecidos, dos problemas de coluna, da amputação de membros pelas "facas elétricas" que cortam as peças, da falta de equipamentos de segurança no trabalho.

7 "Muitas mulheres não conseguem mais diferenciar sua identidade de trabalhadora, de seus papéis de mães, esposas, cozinheiras, domésticas, entre outras funções que geralmente acumulam." (LIMA, 2009, p. 141) 


\section{REFERÊNCIAS}

ABRAMOVAY, R. Paradigmas do capitalismo agrário em questão. Campinas: Ed. Unicamp, 1992.

ALMEIDA, M. W. B. Redescobrindo a família rural brasileira. Revista Brasileira de Ciências Sociais, São Paulo, v. 1, n. 1, p. 66-83, 1986.

BEZERRA, E. M. O trabalho em domicílio das mulheres do Cariri Paraibano no Polo de Confecções do Agreste de Pernambuco. 2011. 132f. Dissertação (Mestrado em Ciências Sociais) - Programa de Pós-Graduação em Ciências Sociais, Universidade Federal de Campina Grande, 2011.

CARNEIRO, M. J. T. Pluriatividade no campo: o caso francês. Revista Brasileira de Ciências Sociais, São Paulo, v. 11, n. 32, p. 89-105, 1996.

CARNEIRO, M. J. T. Agricultores familiares e pluriatividade: tipologias e políticas. In: COSTA, L. F. C.; BRUNO, R.; MOREIRA, R. J. (org.). Mundo rural e tempo presente. Rio de Janeiro: Mauad, 1999.

CARNEIRO, M. J. Política de desenvolvimento rural e o novo rural. In: CAMPANHOLA, C.; GRAZIANO DA SILVA, J. (org.). O novo rural brasileiro. Jaguariúna: Embrapa Meio Ambiente, v. 4, p. 117-149, 2000.

CARNEIRO, M. J. T. Trabalho, "ajuda" e disputas: uma etnografia das confecções de lingerie em domicílios rurais. Estudos de Sociologia, Araraquara, v. 11, n. 20, p. 99-125, 2006.

CASTRO, A. C.; CASTRO, L. B. Do desenvolvimento renegado ao desafio sinocêntrico: reflexões de Antônio Barros de Castro sobre o Brasil. Rio de Janeiro: Campus, 2012.

CHAYANOV, T. Sobre a teoria dos sistemas econômicos não capitalistas. In: SILVA, J. G.; STOLCKE, V. (org.). A questão agrária. São Paulo: Brasiliense, 1981.

COMERFORD, J. Como uma família: sociabilidade, territórios de parentesco e sindicalismo rural. Rio de Janeiro: NuP/Relume Dumará, 2003.

COVER, M.; MENEZES, M. A. Estratégias de renda de trabalhadores migrantes e a mecanização da colheita de cana-de-açúcar: um olhar desde o Sertão Paraibano. Estudos Sociedade e Agricultura, Rio de Janeiro, v. 28, n. 2, p. 458-475, 2020.

GALESKI, B. Basic concepts of rural sociology. Manchester: Manchester University, 1972.

GARCIA JR., A. R. O Sul: caminho do roçado. Estratégias de reprodução camponesa e transformação social. Brasília: Ed. Universidade de Brasília, 1989.

LIMA, A. M. S. As faces da subcontratação do trabalho: um estudo com trabalhadores e trabalhadoras da confecção de roupas de Cianorte e região. 
2009. 357f. Tese (Doutorado em Ciências Sociais) - Programa de Pós-

Graduação em Ciências Sociais, Universidade Estadual de Campinas, 2009.

LIRA, S. M. Os aglomerados de micro e pequenas indústrias de confecções do Agreste/ PE: um espaço construído na luta pela sobrevivência. Revista de Geografia, Recife, v. 23, n. 1, p. 98-114, 2006.

MATTEI, L. A relevância da família rural como unidade de análise nos estudos sobre pluriatividade. Revista de Economia e Sociologia Rural, Brasília, v. 45, n. 4, p. 1055-1073, 2007.

SCHNEIDER, S. Os colonos da indústria calçadista: expansão industrial e as transformações da agricultura familiar no Rio Grande do Sul. 1994. $363 f$. Dissertação (Mestrado em Sociologia) - Programa de Pós-Graduação em Sociologia, Universidade Estadual de Campinas, 1994.

SCHNEIDER, S. A pluriatividade na agricultura familiar brasileira. Porto Alegre: Ed. UFRGS, 2003.

SHANIN, T. Lições Camponesas. In: PAULINO, E. T.; FABRINI, J. E. (org.). Campesinato e territórios em disputa. São Paulo: Expressão Popular, 2008.

SILVA, S. R. A. A juventude na "Sulanca": os desafios da inserção no mundo do trabalho em Taquaritinga do Norte - PE. 2009. 176f. Dissertação (Mestrado em Ciências Sociais) - Programa de Pós-Graduação em Ciências Sociais, Universidade Federal de Campina Grande, 2009.

SOUZA, J. Os batalhadores brasileiros: nova classe média ou nova classe trabalhadora? Belo Horizonte: Ed. UFMG, 2012.

TEPICHT, J. Marxisme et Agriculture : le paysan polonais. Paris: Armand Colin, 1973.

VÉRAS DE OLIVEIRA, R. O Polo de Confecções do Agreste de Pernambuco: ensaiando uma perspectiva de abordagem. In: ARAÚJO, A. M. C.; VÉRAS DE OLIVEIRA, R. (org.). Formas de trabalho no capitalismo atual: condição precária e possibilidades de reinvenção. São Paulo: Annablume, 2011.

WANDERLEY, M. N. B. Raízes históricas do campesinato brasileiro. In: TEDESCO, J. C. (org.). Agricultura familiar: realidade e perspectivas. Passo Fundo: UPF, 1998.

WANDERLEY, M. N. A emergência de uma nova ruralidade nas sociedades modernas avançadas - o rural como espaço singular e ator coletivo. Estudos Sociedade e Agricultura, Rio de Janeiro, v. 8. n. 2, p. 87-145, 2000.

WOORTMANN, K. "Com parente não se neguceia": o campesinato como ordem moral. Anuário antropológico, Rio de Janeiro, n. 87, p. 11-73, 1990. 